\title{
El Museo del Prado imaginario de Jorge Semprún
}

\author{
The imaginary Prado museum of Jorge Semprún
}

\author{
Carlos FERNÁNDEZ PÉREZ \\ karlos.fernandez.perez@gmail.com \\ DOI: http://dx.doi.org/10.18002/da.v0i18.5626
}

Recibido: 26-XI-2018

Aceptado: 3-V-2019

RESUMEN: El escritor y político Jorge Semprún sintió desde niño pasión por la pintura. Muchos de sus libros giran alrededor de un cuadro o de un pintor. A lo largo de su vida Semprún construyó un "museo imaginario" que situó en el Museo del Prado y que estaba formado por las obras de Patinir, Velázquez, Goya y Picasso. Ese museo ideal se hizo realidad en la exposición Picasso: tradición y vanguardia (Madrid, 2006), que Semprún había proyectado quince años antes cuando era Ministro de Cultura. En este artículo estudiamos la formación de ese "museo imaginario" y las razones del mismo.

Palabras clave: Semprún; Museo imaginario; Pintura; Malraux.

ABSTRACT: The writer and politician Jorge Semprún loved painting since he was a little child. Many of his books revolve around a painting or a painter. Throughout his life Semprún built an "imaginary museum" that he placed in the Prado Museum and which comprised works by Patinir, Velázquez, Goya and Picasso. That ideal collection became true with the exhibition Picasso: tradition and avant-garde (Madrid, 2006), which Semprún had planned fifteen years before, when he was Minister of Culture. In this article we are going to study the formation of this "imaginary museum" and the reasons for it.

Keywords: Semprún; Imaginary museum; Painting; Malraux.

"Ese día en el Prado fue de auténtica felicidad"

Jorge Semprún

En el panorama de la literatura europea del último tercio del siglo XX Jorge Semprún (1923-2011) resulta una figura singular por varias razones. Aunque nacido en España, utilizó casi siempre el francés como lengua literaria. El tema recurrente en sus obras, tanto en las de carácter memorialista como en las propiamente novelescas, es la deportación, los campos de concentración nazis y la militancia comunista. Por último, la pintura y los pintores tienen un protagonismo notable en casi la totalidad de sus libros.

Estos tres rasgos tienen su explicación en una biografía que el propio autor calificó en algún momento de "novelesca". Nacido en Madrid en 1923, en el seno de una familia republicana, sufre el exilio en 1936 y enseguida adoptó el francés como lengua propia. Haber pasado durante año y medio por la experiencia de la deportación y el campo de Buchenwald explican la recurrencia de este 
tema en sus obras. En cuanto a la presencia de la pintura en sus libros podemos decir que no es algo extraño en nuestra literatura reciente; baste citar a María Zambrano, Antonio Buero Vallejo o José Ángel Valente. Lo que marca la singularidad de Semprún en este aspecto es la importancia extraordinaria de ese tema en su vida y en su obra, hasta el extremo de que varias de sus novelas se ordenan en torno a algún cuadro o a algún artista.

Dos días después de la muerte de Jorge Semprún, ocurrida el 7 de junio de 2011, el profesor Francisco Calvo Serraller publicaba un artículo periodístico en el que glosaba su figura, en particular su condición de ministro de Cultura durante un período de casi tres años (1988-1991). De aquella época había quedado un libro de memorias importante al que el autor del artículo se refiere con estas palabras: "Una y otra vez sobre el Prado, clandestino o ministro, perseguido, odiado o amado, se comprende que quisiera hacer su propia interpretación del Prado, y de la forma con que lo hiciera un ser como él impelido y volcado en la acción. En Federico Sánchez se despide de ustedes (1993), donde resume su experiencia ministerial, cuenta esta interpretación, ocupando la misma curiosamente casi la mitad de un libro aparentemente político y conflictivo. Por de pronto, no deja de ser sorprendente que en ese libro memorialista, donde todo el mundo esperaba solo un ajuste de cuentas político y, de alguna manera, moral, Jorge Semprún dedicase a sus ensoñaciones en y sobre el Prado casi la mitad de lo escrito"1. Esta y otras ideas apuntadas en este breve artículo las pudo desarrollar el autor en la conferencia que dictó en el Prado pocos días después, en el marco del Homenaje que el museo dedicó a Semprún el 28 de junio de $2011^{2}$.

En efecto, el capítulo cuarto de ese libro supone sin duda toda una revisión in-

\footnotetext{
${ }^{1}$ Francisco Calvo Serraller, "Velázquez, Goya, Picasso...Semprún", El País, 9 de junio de 2011.

${ }^{2}$ Fundación Amigos del Museo del Prado, 13 de diciembre de 2017, enlace web.
}

terpretativa del museo. Y como sugiere Calvo Serraller, ese planteamiento lo venía madurando Semprún desde mucho antes, como prueban las frecuentes referencias a la pintura y a los pintores que hallamos en su obra escrita, relativamente amplia, que había comenzado a publicar a comienzos de la década de los sesenta del siglo pasado. Esa larga y concienzuda reflexión eclosionó en esa etapa de ministro y alcanzó en este libro de memorias su formulación más precisa, aunque no definitiva. Semprún la continuó haciendo en los libros y artículos que publicó y en las conferencias que dictó después de su etapa ministerial, hasta poco antes de su muerte. Nuestra intención en estas páginas es indagar las razones de esa revisión crítica de la pinacoteca madrileña y medir el alcance y consecuencias de la misma. Para ello vamos a fijar tres puntos de partida, a modo de premisas, que consideramos fundamentales para nuestro objetivo.

En primer lugar debemos referirnos necesariamente a André Malraux quien en su libro El Museo Imaginario había desarrollado la idea de metamorfosis: "La metamorfosis no es un accidente: es la vida misma de la obra de arte". Y por tanto, "Toda aproximación capital exige, a su vez, una metamorfosis de la mirada...". "Las obras de arte resucitan en nuestro entorno, no en el suyo"3. Jorge Semprún admiró la talla intelectual y política de Malraux y escribió no pocas páginas sobre él. L'espoir es una novela que lo acompañó toda su vida ${ }^{4}$ y los libros de Malraux son citados con frecuencia por él. En buena medida hizo suyo el aserto del escritor francés: “El museo era una afirmación, el Museo Imaginario es una interrogación" ${ }^{5}$. Semprún

\footnotetext{
${ }^{3}$ André Malraux, El Museo Imaginario (Madrid: Cátedra, 2017), 187-197.

${ }^{4}$ Jorge Semprún, "El combatiente de la guerra civil española", en André Malraux y España (París: Centro cultural español, 1989), 11-31; Adiós, luz de veranos (Barcelona: Tusquets, 1998), 113-114 y "Lúcida y extraordinaria", en Una invitación a la lectura (Madrid: Clásicos del siglo XX, 2002), 113-115.
}

${ }^{5}$ Malraux, El Museo..., 139. 
compartía estas ideas de Malraux y por eso en sus aproximaciones a la pintura y al museo propone ciertamente una metamorfosis de la mirada, un mirar siempre atento y sin prejuicios, propicio a que la obra respire de nuevo ante nosotros y nos interpele.

Dice Franziska Augstein en su biografía del escritor: "Semprún no tiene ninguna teoría literaria"6. Esta afirmación tan rotunda no está justificada, no podemos estar de acuerdo con ella. Es verdad que no fue un teórico de la literatura ni tampoco de la pintura. Pero eso no quiere decir que no fuese permeable a la teoría estética. Le interesaba mucho y en sus obras más maduras hallamos párrafos alusivos a este asunto. Esos libros tienen, como se sabe, nítidos perfiles autobiográficos, pero su poética huye muy conscientemente del realismo tradicional, aquel que registra ordenadamente los acontecimientos que está relatando, para optar por lo que él llamó el "artificio de la memoria". Jordi Gracia define esta praxis narrativa con estas palabras: "En su caso no se trata de contar lo que sucedió para que los demás lo sepan, sino de contar lo que a él le sucede cuando recuerda lo que sucedió allí, lo que le sucede, por tanto, al novelista mientras hace sus novelas"7. Y según este autor, la nueva teoría del género autobiográfico ofrecida por Semprún supuso una verdadera novedad en nuestra literatura, junto a otras aportadas por autores como Juan Benet o Rafael Sánchez Ferlosio. Su poética huye tanto del naturalismo cuanto del idealismo y queda condensada en esta frase que podemos leer en uno de sus últimos libros: "Y las novelas no son la vida auténtica: son mucho más" ${ }^{\text {. }}$ Estamos seguros que lo mismo pensaba de los cuadros que fue incluyendo en su galería imaginaria. Con acierto habló Bernard-Hen-

\footnotetext{
${ }^{6}$ Franziska Augstein, Lealtad y traición. Jorge Semprún y su siglo (Barcelona: Tusquets, 2010), 411.

${ }^{7}$ Jordi Gracia, "Novelar la memoria o la libertad del escritor", en Jorge Semprún o las espirales de la memoria, ed. por Xavier Pla (Zaragoza: Reichenberger, 2010), 87109.

${ }^{8}$ Semprún, Adiós..., 47.
}

ri Levy de "maestro en palimpsestos" en el acto de Homenaje, pues Semprún iba enriqueciendo el significado de las obras, dejándose leer por ellas como había dicho Malraux.

En segundo término podemos decir que la propuesta interpretativa que Jorge Semprún hace del museo del Prado tiene un carácter militante y una potente carga polémica. No solo desea poner al día y superar el canon de la escuela de pintura española fijado por Édouard Manet a mediados del siglo XIX sino que su lectura de algunas obras del museo la hace Semprún contra otras formuladas por autores que gozaban de gran prestigio académico. En concreto las de Michel Foucault y Anthony Blunt, aunque por razones bien distintas, como veremos. Una posición crítica que lógicamente no es caprichosa o gratuita sino que se enmarca en ese nuevo relato de la pintura española que él proponía y que consideraba no solo pertinente sino inexcusable.

En tercer y último lugar hemos de destacar el componente biográfico, que en su caso tuvo una importancia decisiva: "Alguna vez he dicho que yo podría perfectamente escribir una autobiografía en torno al $\mathrm{Mu}$ seo del Prado, tomando las etapas de mi conocimiento, de mi trato con el Prado, como etapas de un proceso de escritura autobiográfica" $^{\prime \prime}$. En efecto, tras repasar su vida se puede concluir que fue en este museo donde se desplegaron las tres edades de la misma, un tópico del arte: el momento iniciático de la niñez, la juventud clandestina y la madurez oficial. Cuando Semprún habla del museo del Prado lo hace también de sí mismo, pues en aquellos pasillos y salas están buena parte de las obras que jalonaron su vida. Pero no hay que ver en esto un afán narcisista o mitómano pues su mirada incorpora siempre aspectos de la historia de España y de Europa del siglo XX que envuelven y desbordan lo estrictamente personal.

\footnotetext{
${ }^{9}$ Jorge Semprún, “El paso de la laguna Estigia. Joachim Patinir", en Obras maestras del Museo del Prado (Madrid: Fundación Amigos del Museo del Prado-Electa, 1996), 107.
} 
En síntesis, la tesis que deseamos proponer en este artículo es la de que a la manera de Malraux, Jorge Semprún también construyó a lo largo de su vida un museo imaginario, aunque con alguna diferencia reseñable respecto a su mentor. Si el museo de aquel se nutría esencialmente de la fotografía, como muestra la famosísima imagen suya realizada por Maurice Jarnoux para $\mathrm{Pa}$ ris Match en 1953, el del autor español se fue conformando lentamente, al paso de los avatares de una vida ciertamente novelesca. Fue un museo formado en exclusiva por obras de pintura, por un número pequeño de cuadros de una reducida nómina de pintores repartidos por las pinacotecas europeas, pero que tuvo en el Prado su núcleo original y más importante $^{10}$. Su vida, o mejor la memoria de su vida y en particular su deportación a Buchenwald, giró en torno a ese museo. Su obra literaria da cuenta de su proceso de construcción y del esfuerzo por interpretarlo una y otra vez. Para ello necesitó recurrir, a una nueva poética en la que es esencial lo que el profesor Jordi Gracia llamó "la noción de imperfección". Apuesta literaria que en su opinión tuvo gran importancia: "El relato de la experiencia de los campos, lejos de la poética de la autobiografía, ha exigido de Semprún la reinvención de un formato novelesco y un punto de vista narrativo apto para esa forma de la complejidad humana. Y ese es, con el de Benet, un auténtico injerto renovador en nuestra cultura, como si ambos hubiesen sido larvas de extranjería en un contexto histórico todavía muy indigenista o demasiado ausente de la Europa intelectual de su tiempo"11. En esta propuesta narrativa es donde la pintura y los pintores ocupan un lugar fundamental. Los nombres de Patinir, Vermeer de Delft, Artemisia Gentileschi, Velázquez, Goya, Picasso, Tapies, Nicolas de

${ }^{10}$ Jorge Semprún, Federico Sánchez se despide de ustedes (Barcelona: Tusquets, 1979), 181-182 y Aquel domingo (Barcelona: Tusquets, 1999), 373.

${ }^{11}$ Gracia, "Novelar la memoria...", 109.
Staël, Adami, Music pueblan las páginas de sus libros ${ }^{12}$.

Pero el museo imaginario no solo se nutre de obras de arte. Son igualmente esenciales la interpretación que se hacen de las mismas y las relaciones que se van entretejiendo entre unas obras y otras. $Y$ creemos que es en este sentido cuando nuestra propuesta cobra su verdadera dimensión. Porque Jorge Semprún no se limitó a seleccionar una serie de obras sino que ha encontrado en ellas un sentido personal realmente complejo pero de gran coherencia, que está más allá de los discursos académicos. Discursos que en modo alguno desatendía pero que le resultaban insuficientes para dar cuenta de lo que para él representaban las obras de esa pinacoteca ideal. Y si tenemos que expresar con palabras cual era la intención profunda de este museo íntimo e imaginario hemos de recurrir seguramente a una frase de André Malraux que él citó más de una vez en sus libros y conferencias: “...busco la región crucial del alma donde el Mal absoluto se opone a la fraternidad". Las pinturas del Prado de las que vamos a hablar y otros cuadros de los pintores que hemos citado más arriba se mueven en torno a esta idea central que condensa los avatares de una vida larga y fecunda.

El museo imaginario, tal y como lo formuló Malraux, no es un lugar físico. Está formado por obras de arte que habitan un universo mental que se va conformando a impulsos y que por eso mismo nunca puede darse por concluido: es un edificio en construcción. Creo que es posible fijar dos líneas sobre las cuales se ordena este museo imaginario que atribuimos a Jorge Semprún, líneas que no son paralelas sino que se cruzan en varios momentos como veremos. La primera se materializa en el binomio Patinir-Velázquez. Los cuadros que Semprún más admiraba de estos artistas -El paso de la laguna Estigia y Las meninas- están sin duda muy

\footnotetext{
${ }^{12}$ Carlos Fernández, "Pintura y memoria en las novelas de Jorge Semprún", Historia, antropología y fuentes orales, $\mathrm{n}^{\circ} 46$ (2011), 47-59.
} 
ligados a los años más activos del escritor desde el punto de vista político: el exilio, la deportación y la actividad política clandestina en España. Fue en esa etapa (1940-1960, aproximadamente) cuando estos cuadros cobraron para él un significado esencial. La segunda se organiza sobre el eje Goya-Picasso y fue cobrando solidez a partir del momento en que Semprún dejó de ser un activista clandestino en los primeros años sesenta y pasó a ser un escritor famoso y, sobre todo, cuando fue nombrado Ministro de Cultura (1988-91). Fue en estos años cuando él puso en marcha un proceso de reflexión sobre el lugar de Picasso en la pintura española y eso lo llevó a considerar como necesaria su presencia en el Museo del Prado. Como vemos, en este caso incorpora a un artista que no estaba en las salas de la pinacoteca madrileña. Y lo hace no solamente para dar curso al deseo de Picasso sino para proponer, como veremos, una nueva narrativa de la pintura española. Vamos a exponer todo esto con más detalle.

\section{PATINIR Y VELÁZQUEZ}

En ese capítulo cuarto del libro de memorias del que venimos hablando Semprún confiesa: "Podría contar mi vida...con referencia a Las meninas de Velázquez, rondando en torno a este cuadro. No porque no haya en el Prado cuadros que me conmuevan más, inspirándome sin duda movimientos más profundos del corazón y del espíritu"13. A Jorge Semprún le gustaba recordar que vivió parte de su niñez a dos pasos del museo del Prado. Entre 1928-1936 su familia ocupó un piso en el número 12 de la calle Alfonso XI. Fue un hecho que acabó siendo fundamental en su vida $y$, como tal, recurrente en su obra literaria: "Toda mi infancia he vivido a unos centenares de metros del Prado... Los domingos, a menudo, mi padre nos llevaba a tres de los hermanos - Gonzalo, Álvaro y yo- a visitar el museo. Las salas estaban entonces prácticamente vacías... El Prado era entonces un lugar austero, desierto, de un

\footnotetext{
${ }^{13}$ Semprún, Federico Sánchez..., 181.
}

ambiente un poco enrarecido, que solo vivía para y por la pintura...Pero no estoy haciendo un alegato a favor de los felices viejos tiempos de los museos vacíos, deliciosamente reservados a una élite..."14. La pintura entró en su vida en los años de la infancia. $\mathrm{Y}$ lo hizo de manera decisiva.

No hace falta que imaginemos el recorrido que solía hacer José María Semprún Gurrea por las salas del museo pues su hijo nos dio datos precisos sobre el particular ${ }^{15}$ : los cuadros de historia, la pintura religiosa, la obra de Goya...El desnudo femenino estaba censurado. En aquellas visitas el niño Jorge Semprún descubrió algunas obras que lo iban a acompañar toda la vida. Entre ellas una pequeña tabla de Joachim Patinir, cuadro sobre la que iría proyectando, en sutiles veladuras, las sucesivas etapas de su existencia: "Por lo cual, la memoria infantil, la memoria de la clandestinidad, la memoria de la vida normal, después, y hasta la memoria ministerial, todas las memorias sucesivas del Prado pueden coincidir en esa sala de los primitivos flamencos, porque allí es donde descubrí El paso de la laguna Estigia"16. Podemos suponer con buenas razones que este es uno de esos cuadros que conmovían profundamente a Semprún en el Prado, por encima de Las meninas. Hasta el punto de que organizó en torno a él la trama de su novela $L a$ montaña blanca y le dedicó una conferencia monográfica en el propio museo.

No sabemos qué contaba José María Semprún a sus hijos delante de la tabla de Patinir, pero podemos suponerlo verosímilmente. La obra, como se sabe, recurre desde un punto de vista iconográfico a tradiciones paganas y cristianas y las funde en una escena capaz de interesar a un muchacho adolescente: “En dicho lienzo (sic) se reflejan, de

\footnotetext{
${ }^{14}$ Semprún, Federico Sánchez..., 156-157.

15 Jorge Semprún, Vivir es resistir (Barcelona: Tusquets, 2014), 135-136; Soledad Fox Maura, Ida y vuelta. La vida de Jorge Semprún (Barcelona: Debate, 2016), 253-

${ }^{16}$ Semprún, “El paso...”, 105-111.
} 254. 
forma original, personal, aunque enmarcados en las referencias culturales y mitológicas de la tradición, los temas obsesivos, recurrentes del tránsito de la vida a la muerte, del Paraíso y del Infierno, de la travesía en la barca de Aqueronte, de una orilla a otra de la laguna Estigia"17. No resultará inoportuno recordar en este punto que en 1932 muere Susana Maura Gamazo, madre de Semprún, a los 37 años de edad. Esa muerte prematura dejó una huella profunda en aquel niño de apenas ocho años. Si el azul-patinir había simbolizado hasta ese momento la alegría de la niñez, El paso de la laguna Estigia hubo de cobrar para él un significado muy diferente en aquel momento tan dramático y fue a partir de entonces el espejo en el que Semprún se miró y vio reflejadas las escenas más intensas de su vida.

A mediados de 1953 Jorge Semprún regresó clandestinamente a España. Muchas cosas habían pasado desde 1936: residencia con su padre en La Haya, estudios en París, la resistencia, el campo de concentración, la militancia comunista. $\mathrm{Y}$ a partir de ahora, en los próximos diez años, la política antifranquista. Durante sus estancias en Madrid a lo largo de esa década, las visitas al Prado fueron frecuentes y en ellas el cuadro de Patinir fue enriqueciéndose con un simbolismo más personal y complejo, emanado de la experiencia del maquis y de Buchenwald. Tras ser detenido en el mes de octubre de 1943, había sido sometido a un duro trato por la Gestapo. Semprún no habló demasiado de ello, pero la tortura dejó profunda y perenne huella en él ${ }^{18}$, hasta el punto que la laguna Estigia de su niñez por la que navegaba Caronte pasó a ser también un símbolo de la propia muerte, de la pulsión suicida que acechaba a los supervivientes del holocausto $^{19}$. Prueba de ello es que al término de su novela La montaña blanca el personaje que lle-

${ }^{17}$ Semprún, "El paso...", 106.

${ }^{18}$ Jorge Semprún, Ejercicios de supervivencia (Barcelona: Tusquets, 2016), 61-66; Augstein, Lealtad y traición..., cap.4.

${ }^{19}$ Augstein, Lealtad y traición..., 110. va el nombre de uno de sus seudónimos de la clandestinidad, Juan Larrea, escritor español exiliado, combatiente en la resistencia y deportado, se suicida en el Sena acordándose de la tortura y de Patinir: "Se ahogaba; forcejeó, recordó, en un relámpago cegador la bañera de la Gestapo...supo que se ahogaba en el rìo de Patinir...El agua del rìo Estige se lo llevó en sus ondas" ${ }^{20}$.

El cuadro de Patinir se cierra en su parte alta con un cielo de nubes algodonosas que flotan sobre la línea del horizonte. En más de una ocasión, en sus libros autobiográficos, Jorge Semprún se refiere al humo del crematorio que había en el campo de Buchenwald, a sus compañeros que se habían esfumado y convertido en humo. El humo es un tópico trágico en la literatura de los campos ${ }^{21}$. Los presos que no habían logrado sobrevivir tendrían una tumba en las nubes. Tras haber pasado por el campo de concentración alemán y haber regresado clandestinamente a España en 1953, la visita de Semprún al Prado, a la sala de los pintores flamencos, se habría hecho más compleja y más densa. Aunque no lo dejó escrito expresamente podemos conjeturar que el cielo de Patinir le evocaría necesariamente aquella tumba en la que, al hilo de un verso de Paul Celan, imaginaba él a sus camaradas muertos cuando visitó de nuevo el campo de concentración en 1992. Aquellos deportados no llegaron a ocupar la barca de Caronte, se convirtieron en humo. Su tumba estaba en las nubes, en aquel cielo grisáceo y ligero de Patinir ${ }^{22}$.

Cuando en 1995 el museo del Prado organizó un curso de conferencias sobre obras maestras de la pintura que cuelgan en sus salas, el cuadro elegido por Jorge Semprún fue precisamente este de Patinir. En aquel

${ }^{20}$ Jorge Semprún, La montaña blanca (Madrid: Alfaguara, 1987), 301-302.

${ }^{21}$ Jorge Semprún, La escritura o la vida (Barcelona: Tusquets, 1995), 22-25; Liana Millu, El humo de Birkenau (Barcelona: Acantilado, 2005).

${ }^{22}$ Jorge Semprún, “Una tumba en las nubes", en Pensar en Europa (Barcelona: Tusquets, 2006), 141-156. 
año se cumplía el cincuentenario de la liberación de los campos de concentración nazis. En ese mismo año publicó en castellano $\mathrm{La}$ escritura o la vida, su mejor libro sobre la experiencia de Buchenwald, "patria extranjera a la que siempre acabo volviendo" ${ }^{23}$. Semprún tenía más de setenta años y una vida novelesca a sus espaldas. La pequeña tabla de Patinir se acabó convirtiendo para él en un memento mori, al igual que le ocurrió a su álter ego Larrea. Ese tópico del arte recorre de arriba abajo el texto de la conferencia: "Por eso puede Juan Larrea, y puede cualquiera que descubra a Patinir, acordarse de él no solo en el momento de la muerte, sino en cualquier momento crucial de la vida. Encontrarse frente a ese cielo, frente a esa laguna, más bien río Estigio que es el río de la vida, con, de un lado, la representación del Paraíso, con esos edificios cristalinos, tan directamente inspirados por El Bosco, que puede ser el palacio de la ensoñación, de la utopía de una vida feliz, y del otro lado, las escenas minuciosas del Infierno, es como encontrarse al comienzo y al final del viaje. No solo el viaje de Patinir, el largo viaje de la vida misma" ${ }^{24}$. Este párrafo, lleno de alusiones autobiográficas, sintetiza mejor que cualquier otro lo que esta escena acabó significando para Semprún y por ello se solía situar ante ella en los momentos importantes de su vida, no solo en los largos años de clandestinidad sino más tarde; incluso cuando en 1988 Felipe González lo nombró ministro de Cultura ${ }^{25}$.

Si nos hemos demorado en repasar la presencia de este cuadro de Patinir en la vida y obra de Jorge Semprún es porque ofrece un buen ejemplo de la manera que él tenía de acercarse a la pintura. Esa conferencia que le dedicó en el museo del Prado en 1995 condensa a la perfección ese método, en el que combinaba tres aspectos, a saber: el his-

\footnotetext{
${ }^{23}$ Semprún, La escritura..., 19.

${ }^{24}$ Semprún, "El paso...", 111.

${ }^{25}$ Semprún, Federico Sánchez..., 95; Juan Cruz Ruiz, Especias en extinción (Barcelona: Tusquets, 2013), 279.
}

tórico, el simbólico y el autobiográfico. Semprún se documentaba bien sobre las obras, incorporaba la bibliografía en su discurso, pero la lectura simbólica y la interpretación de la misma se alejaba con frecuencia de los estudios académicos para ofrecer otra muy ligada a su biografía, a momentos muy concretos de su vida. Por otro lado, el método expositivo de Semprún tiene también un rasgo muy particular. Al igual que en sus novelas, desdeña el orden cronológico y prefiere un vaivén temporal hacia adelante y hacia atrás que él tomó de Faulkner, de Proust y del propio Malraux. Eso le permite un juego con el tiempo que suele ser muy atrevido y brillante, aunque no siempre compartido por los especialistas. Baste un ejemplo: en ninguno de los libros más importantes que se han publicado recientemente en España sobre Patinir -el catálogo de la exposición en el Prado (2007) y la monografía de Javier Maderuelo (2011) - se cita a Semprún. Su aproximación a la obra y la lectura de la misma están en otro plano. En el plano de las ideas de "metamorfosis" y de "museo imaginario", tomadas de Malraux precisamente.

En el museo que Semprún fue construyendo a lo largo de su vida Las meninas ocupan un lugar exclusivo: "En este periplo imaginario, sin embargo, todo empieza y concluye ante Las meninas de Velázquez. Mi vida está ligada a esta obra fascinante, se aparta de ella y vuelve a ella sin cesar, encontrándola siempre en su camino" ${ }^{26}$. De este modo tan indubitable establece su relación con la tela de Velázquez, una experiencia ciertamente larga en el tiempo y compleja en significados. En la sala de unos pocos metros cuadrados en la que estaba el cuadro se cruzó con un personaje desconocido para él: "Allì fue, en 1954, donde me encontré con Nicolas de Staël. O más bien, donde me encontré a un desconocido que resultó ser $\mathrm{Ni}$ colas de Staël"27. Este pintor de origen ruso y afincado en Francia había descubierto el Prado en el verano de 1935, cuando era un

\footnotetext{
${ }^{26}$ Semprún, Federico Sánchez..., 182.

${ }^{27}$ Semprún, Federico Sánchez..., 185.
} 
artista novel, justo cuando también lo hacía Semprún de la mano de su padre. Vuelve al Prado en octubre de 1954, siendo ya un pintor consagrado, y es en esa visita cuando se produjo el cruce de miradas ante la tela maestra de Velázquez. Aquel momento tuvo una gran importancia para Semprún, quien así lo recreaba cuarenta años más tarde: "Estaba ante el cuadro de Velázquez, decía de él cosas pertinentes, apasionantes, con una voz grave, enfebrecida, ronca, a alguien que le acompañaba. Yo me encontraba un poco apartado, pero el desconocido debió de sentir la densidad casi dolorosa de la atención que prestaba a sus palabras, de mi silencio cautivado...Uno o dos años más tarde descubrì que el desconocido del Prado era el pintor Nicolas de Staël"28. Lamentablemente, fue un descubrimiento post morten, pues el pintor se había suicidado en Antibes el 16 de marzo de 1955.

En alguna otra ocasión posterior evocó Semprún con mucho detalle ese momento: "Mais le jour dont je parle, la petite sale n'etait pas vide. Trois hommes se tenaient devant "les Ménines", à mon grand regret. L'un d'eux, un grand type que parlait français, détaillait aux deux autres les beautés et les mystères de cette toile. J'ai été saisi par la violence et la rigueur des paroles de l'inconnu, la beauté percutante et pertinente de son discours. Jamais plus je n'ai entendu parler de Vélasquez avec une telle passion lumineuse. Je suis resté figé, quelques pas derrière l'inconnu, buvant ses paroles... Vélasquez e Nicolas de Staël; je ne puis parcourir le Prado sans penser à ce jour d'autrefois. A la voix précipitée, hachée, de ce dernier parlant à ses compagnons $d u$ mystère lumineux de la toile du premier... Mais "les Ménines" ne sont plus accrochées dans la petite salle d'antan. Elles trônent aujourd'hui dans la salle principalle de Vélasquez... Mais je regrette infiniment l'emplacement d'antan. Dans la grande salle remplie de touristes, je n'arrive plus à entendre la voix de Nicolas de Staël, à qui je dois l'un des plus belles émotions de ma vie"29.

\footnotetext{
${ }^{28}$ Semprún, Federico Sánchez..., 185-186.

${ }^{29}$ Jorge Semprún, "Les Ménines de Vélasquez", Le Nouvel Observateur, 4 de agosto de 2005.
}

Hay en esta larga cita tres aspectos que merecen atención. En primer término, la referencia a la sala en la que se exponía el cuadro en aquella fecha. La descubrió cuando siendo niño visitaba con su padre el museo a mediados de los años treinta del siglo pasado. La tela ocupaba en solitario desde 1928 la sala $\mathrm{XV}$, enfrentada a un espejo ${ }^{30}$. Aquel espacio íntimo y reservado, con el mismo espejo, lo encontró Semprún en 1953 cuando regresó clandestinamente a España y entró de nuevo el Prado tras casi veinte años de exilio. La salita de Las meninas seguía allí y acabó convirtiéndose para él en una especie de santuario del que nunca se marchó del todo, en el que se sentía seguro al tiempo que disfrutaba de la pintura ${ }^{31}$. La recordó siempre como un lugar privilegiado de su memoria. Su dimensión reducida tenía sin duda la facultad de resaltar la profundidad del taller en el que Velázquez sitúa la escena. Resulta verosímil pensar que el propio Nicolas de Staël hubiera hecho aquel día alguna observación a ese espacio de la tela y a su organización interna, pues a su regreso a Antibes pintó varios cuadros de gran formato que tiene como tema su atelier, un interior sin figuras de potentes líneas ortogonales y sutiles transiciones cromáticas en el que los estudiosos de su obra han visto con razón el eco de la obra de Velázquez ${ }^{32}$.

En segundo lugar dice Semprún que las palabras apasionadas pronunciadas ante Las meninas por aquel desconocido "fundaron mi ulterior atención admirativa a la pintura de Nicolas de Staël" ${ }^{\prime 33}$. Este sentimiento ya la pudimos comprobar leyendo su novela $\mathrm{La}$ montaña blanca, en la que Antoine de Stermaria pinta una serie de telas que llevan el nombre de algunas de Staël. Pero es que además,

\footnotetext{
${ }^{30}$ Javier Portús, "La sala de las Meninas en el Museo del Prado o la puesta en escena de la obra maestra", Boletín del Museo del Prado, T. XXVII, no 45 (2009), 100-128.

${ }^{31}$ Semprún, Federico Sánchez..., 184-185.

${ }^{32}$ Nicolas de Staël. Retrospectiva (Madrid: Museo Nacional Centro de Arte Reina Sofía, 1991), 158.

${ }^{33}$ Semprún, Federico Sánchez..., 187.
} 
siendo ministro de Cultura y en el momento de acompañar a la reina de Inglaterra al museo del Prado en el mes de octubre de 1988, Semprún concibió el proyecto de una exposición retrospectiva de su obra y que tuvo lugar en el Centro de Arte Reina Sofía, entre el 7 de octubre y el 2 de diciembre de 1991. En esa fecha Semprún había abandonado ya la cartera de Cultura pero no por ello dejó de colaborar en el catálogo de la muestra. Su contribución lleva por título Aquí culmina la pintura moderna..., una breve pero enjundiosa meditación sobre la pintura de Nicolas de Staël y sobre la propia figura de este pintor exiliado a quien considera "el último gran clásico de la modernidad"34. De esta manera tan fructífera culminaba la relación de Jorge Semprún con aquel desconocido que de manera azarosa se había cruzado en su vida en el lejano año de 1954, en una pequeña sala del museo del Prado. Y lo hace de un modo particular, pues en el texto escrito por el ministro resuena con fuerza la voz de André Malraux, quien había concluido su ensayo sobre Goya con la frase Ensuite, comence la peinture moderne; esa pintura de la cual Nicolas de Staël sería la brillante culminación.

Y por último, resulta llamativo la profunda impresión que aquel encuentro fortuito dejó en Semprún: la belleza pertinente del discurso de aquel desconocido, la pasión luminosa con la que pronunciaba sus palabras. ¿Qué decía Nicolas de Staël aquel día de 1954 en el Museo del Prado ante la tela de Velázquez? No lo sabemos. Jorge Semprún no entra en detalles, pero tenemos manera de averiguarlo al menos aproximadamente. Porque esas palabras habrían de ser muy parecidas a las que el pintor empleó en la conocida carta que el 29 de octubre de 1954 le envía desde Madrid al galerista Jacques Dubourg: "Quelle joie! Solide, calme, inébranlablement enraciné, peintre des peintres à égale distance des rois et des nains, à égale distance de lui-même et des autres. Maniant le miracle à chaque touche, sans hésiter en hésitant, immense

\footnotetext{
${ }^{34}$ Jorge Semprún, "Aquí culmina la pintura moder-
} na", en Nicolás de Staël..., 20. de simplicité, de sobrieté, sans cesse au máximum de la couleur, toutes réserves à lui, hors de lui et là sur la toile. Donne l'impression claire d'êttre le premier pilier inébranlable de la peinture libre, libre. Le Roi des Rois"35. La carta de Staël muestra una admiración sin límites no solo hacia la pintura sino ante la figura misma de Velázquez.

El encuentro con Nicolas de Staël dejó una huella perenne en la manera de ver Las meninas que tuvo Semprún y nos ayudará a entender su crítica a Michel Foucault, quien en su obra Les mots et les choses ${ }^{36}$ (Las palabras y las cosas, 1966) había propuesto en el primer capítulo del libro una interpretación del cuadro. A ella se refirió Semprún en más de una ocasión. Cuando visitaba el museo acompañando a Isabel II recordó al filósofo francés: "Me acuerdo una vez más de Michel Foucault. En su falsa y brillante digresión a propósito de Las meninas, se preguntaba sobre el lugar del rey en el lienzo. Pero sin duda hay que preguntarse primero por el lugar del pintor. Ocupa el centro de la tela de Velázquez, aquel real pintor, todo gira en torno a él, él es quien organiza el espacio de la pintura. ¿El espacio del mundo? Pero en La familia de Carlos IV la figura de Goya ya solo es una vaga sombra a la sombra del poder. Mejor dicho, el pintor elige la sombra para apartarse del poder real, para tomar sus distancias. En el Guernica ya no hay figura del pintor. Ni siquiera la sombra del pintor. Ya solo queda la Historia, el horror desnudo de la Historia" ${ }^{37}$. No resulta difícil escuchar el eco de las palabras de Nicolas de Staël en la crítica que Semprún hace a Foucault, resaltando la figura del pintor y divagando sobre la relación del artista y el poder.

En unas páginas anteriores del libro de memorias plantea Semprún su crítica a Fou-

${ }^{35}$ El texto completo puede consultarse en Nicolas de Staël, Lettres à Jacques Dubourg (London: Taranman, 1981).

${ }^{36}$ Michel Foucault, Les Mots et les choses (Paris: Gallimard, 1966).

${ }^{37}$ Semprún, Federico Sánchez..., 203. 
cault en un plano filosófico: "Su ensayo Las palabras y las cosas se abre con páginas brillantes a propósito de este cuadro. Sumamente brillantes pero profundamente falsas. Diría incluso que de una falsedad radical...Se trata de una visión ideológica que determina la lectura de las significaciones posibles del cuadro, visión inducida por instancias ideales que no tienen relación alguna con la pintura ni con las reglas o desarreglos que le son propios. La visión que enturbia la mirada de Foucault -que la hace muy aguda, más bien, muy brillante, pero ciega a la realidad material e histórica que el cuadro representa, de la que propone astutamente diversas interpretaciones-, esa visión es la del antihumanismo teórico. El hombre ya sólo es un pliegue en el paisaje histórico, una redundancia retórica que el curso de las cosas tiende a difuminar. El hombre deja de ser el objeto de la filosofía en el momento en que Foucault escribe Las palabras y las cosas, se convierte en el mal sujeto de ella" ${ }^{38}$. Semprún se hace eco de los párrafos que cierran el libro del filósofo francés para mostrar su oposición frontal a la tesis que en él se formula. Y, de paso, a una de sus consecuencias especialmente importante en el campo de la teoría del arte; nos referimos a lo que conocemos como "el desvanecimiento del sujeto" ${ }^{\prime \prime 9}$.

\section{GOYA-PICASSO}

Pero no solo resultan interesantes estas cuestiones en el contexto de la polémica con Foucault sino también porque en ellas Semprún coloca a Picasso en la senda de Goya, lo cual es una manera implícita de reivindicar su presencia en el Prado. Vamos a verlo con algún detalle. En 1991, poco después de dejar el ministerio, dio Semprún una conferencia invitado por la Fundación Amigos del Museo del Prado. En ella repasó la biografía

\footnotetext{
${ }^{38}$ Semprún, Federico Sánchez..., 189.

${ }^{39}$ Carlos Thiebaut, "La mal llamada postmodernidad (o las contradanzas de lo moderno)", en Historia de las ideas estéticas y de las teorías artísticas contemporáneas, ed. por Valeriano Bozal (Madrid: Visor, 1996), vol II, 311-327.
}

de Francisco de Goya e interpretó la modernidad de su pintura. Identificó la novedad de su arte, comparándolo con Velázquez, precisamente en lo referente a la mirada del pintor y su nueva visión de la historia y de la condición humana ${ }^{40}$. Reparó, como ya había hecho Malraux, en la figura de Judith que vemos en una de las escenas de la Quinta del Sordo. Si este la interpretaba como "turbadora y voluminosa Némesis", Semprún la ve como un "personaje de un perfil totalmente picassiano". Para concluir su charla, recordó una vez más la frase con la que Malraux cierra su ensayo sobre Goya: Ensuite, comence la peinture moderne $e^{41}$. La autoridad del escritor francés es reconocida por el español. Para ambos la luz de la pintura de Goya ilumina el arte de Picasso. Por eso en aquella conferencia hizo la siguiente confesión: "Y fue un sueño mío que no pudo realizarse, organizar la confrontación o el encuentro bajo el patrocinio del difunto Malraux, dentro del comentario de su voz y su discurso sobre el arte, del Picasso del Guernica y del Goya del Tres de mayo, que son los dos pintores $-\mathrm{y}$ los dos son españoles- que mejor y con más profundidad han captado los desastres de la guerra, que han captado el punto de vista de los vencidos sobre la guerra, y no el punto de vista de los vencedores" ${ }^{42}$. En efecto, en las últimas páginas de La cabeza de obsidiana (1974) hablaba Malraux del "imprevisible Prado en el que España espera a Guernica y donde el mejor Goya esperaba al joven Picasso" $^{\prime 4}$.

Fue en 1990 cuando el ministro Semprún entrevió como un proyecto plausible la idea del politico francés. Así lo dice en su li-

${ }^{40}$ Jorge Semprún, "Francisco de Goya", en Veintitrés biografías de pintores. Museo del Prado (Madrid: Mondadori, 1992), 439-453.

${ }^{41}$ André Malraux, Saturne. Essai sur Goya (Paris: La Galerie de la Pleiade, 1950). Hay traducción parcial en André Malraux y España (París: Centro cultural español, 1989), 135-153.

${ }^{42}$ Veintitrés biografías..., 451.

${ }^{43}$ André Malraux, La cabeza de obsidiana (Buenos Aires: Sur, 1974), 195. 
bro de memorias: "Pienso en esa serie inexistente de salas del Prado que comenzaría con Las meninas de Velázquez y concluiría con el Guernica, pasando por los Fusilamientos del 3 de mayo y la pintura negra de Goya. Pienso que debería hacerse sobre este tema por lo menos una exposición temporal para tomar el pulso de nuestra historia. No solo de la historia de nuestra pintura..." 44 . El proyecto buscaba sin duda cumplir la voluntad que Picasso le había expresado en La Californie, su casa de Cannes: "Él quería estar en el Prado para verse confrontado con Velázquez y con Goya, ése era su violento deseo" ${ }^{\prime 4}$. Pero junto al lejano aliento de Malraux este proyecto ideal se hace bajo el recuerdo de Anthony Blunt. Mientras acompañaba a Raísa Gorbachova en el Casón del Buen Retiro para contemplar el cuadro de Picasso, Jorge Semprún se acordó de Blunt y del artículo que sobre él había publicado George Steiner en The New Yorker diez años atrás, con el título "The Cleric of Treason" ${ }^{46}$ : “ ¿Se me ocurrió aquel día la confrontación entre Pablo Picasso y Francisco de Goya? ¿Y colocar frente al Guernica, en esta sala del Casón, los Fusilamientos del 3 de mayo? No es imposible" ${ }^{\prime 7}$. El artículo de Steiner apareció en 1980, al año siguiente de que Margaret Thatcher revelara en el parlamento británico que Blunt había sido espía soviético. En sus primeros años como agente al servicio de la URSS ejerció también como crítico en el periódico The Spectator. Como tal, el futuro gran historiador del arte publicó una dura columna sobre el Guernica, con motivo de su exposición en París en 1937. Sus juicios eran severos y provocaron en su momento un intenso debate entre los especialistas ${ }^{48}$. Las razones de

${ }^{44}$ Semprún, Federico Sánchez..., 202-203.

${ }^{45}$ Semprún, Federico Sánchez..., 176.

${ }^{46}$ Georges Steiner, "El erudito traidor", en Georges Steiner en The New Yorker (Madrid: Siruela, 2009), 27-63.

${ }^{47}$ Semprún, Federico Sánchez..., 175.

${ }^{48}$ Algunos documentos de dicho debate pueden encontrarse en el Catálogo de la exposición Piedad y terror en Picasso (Madrid: Museo Nacional Centro de Arte Reina Sofía, 2017), 145-154. los mismos las expone muy bien Steiner en el artículo arriba mencionado y hay que entenderlas en el debate que se desató en los años treinta de la centuria pasada sobre la función del arte y la relación del artista con el poder político, en el contexto de las revoluciones soviética y mexicana.

En el libro de memorias de su etapa ministerial Jorge Semprún descalifica al historiador británico con palabras gruesas y sin entrar en grandes matices: "Yo observaba los gestos y remilgos de Raísa Gorbachova, me acordaba de las estupideces que Anthony Blunt había escrito a propósito del Guernica...mientras Raísa Gorbachova se desinteresa del cuadro de Picasso como si estuviera de acuerdo con el juicio perentorio y despreciativo de Anthony Blunt"49. Estas desabridas frases tienen mucho de ajuste de cuentas con quien había sido compañero de viaje en los duros años del estalinismo. Si Semprún había sucumbido a la "glaciación ideológica" de aquella etapa, las opiniones de Blunt habían estado lastradas por la "glaciación artística" que había supuesto la doctrina del realismo socialista ${ }^{50}$. Aquella exposición imaginada habría de servir sin duda para desmontar las críticas vertidas medio siglo antes y volver a un tema que siempre le interesó a Semprún: la relación del arte y el poder.

Esta exposición no se realizó en ese momento. El ministro era consciente de la dificultad: "No haberlo conseguido es una de las cosas que más lamento de mi época ministerial" ${ }^{21}$. Habrá de esperar quince largos años: se celebró en 2006 en los museos del Prado y Reina Sofía con el nombre de Picasso. Tradición y vanguardia. La colaboración de Semprún en el catálogo de la misma supone un reconocimiento explícito a André

\footnotetext{
${ }^{49}$ Semprún, Federico Sánchez..., 175 y 179.

${ }^{50}$ Felipe Nieto, La aventura comunista de Jorge Semprún (Barcelona: Tusquets, 2014), cap. 3; Jorge Semprún, "El arte en la época de la mundialización", en Pensar en Europa (Barcelona: Tusquets, 2006), 203-224.

${ }^{51}$ Semprún, Federico Sánchez...,180.
} 
Malraux y una lectura del Guernica en la senda de la pintura negra de Goya. Y, de paso, una crítica en los planos ideológico y estético, mucho más matizada e interesante que la que había hecho en su libro de memorias, a la posición que había adoptado Anthony Blunt en $1937^{52}$. La exposición, como dice él mismo, supuso un hito notable para entender el arte de Picasso como culminación de nuestra tradición artística pero también para ofrecer otra síntesis de la misma y al tiempo superar "una visión de la pintura española mostrencamente nacionalista", como muy bien expresó Calvo Serraller en el acto de Homenaje a Semprún.

Después de todo lo dicho y para concluir, cabe preguntarnos por las razones últimas del museo imaginario de Jorge Semprún. El Prado fue su casa y en él pasó muchas horas a lo largo de su vida. En sus salas empezó desde niño a disfrutar de la pintura y a meditar sobre ella y los pintores. De esa meditación, realizada al hilo de una vida que condensa buena parte de la historia de Europa del siglo $X X$, fue surgiendo a lo largo de toda una vida una pinacoteca ideal, formada por obras del Renacimiento a nuestros días. Constituyó un universo mental que existía en la memoria de Semprún y que encontramos en sus libros autobiográficos y novelas, en sus entrevistas y conferencias. El museo se fue haciendo, como hemos visto, paso a paso, al calor de visitas, lecturas, encuentros azarosos y desencuentros polémicos Fue también un museo nunca terminado, siempre abierto a nuevas interpretaciones, al que el autor volvió una y otra vez puesto que Semprún no se interesó solo por lo que pasaba en el cuadro sino por lo que le ocurría a él cuando se colocaba delante de la tela y desplegaba sobre ella "el artificio de la memoria" ${ }^{53}$. Todo ello suponìa una reivindicación

\footnotetext{
52 Jorge Semprún, "Ahora empieza la pintura moderna", en Picasso. Tradición y vanguardia (Madrid: Ministerio de Cultura, 2006), 21-25.

${ }^{53}$ Carlos Fernández, "Jorge Semprún y las estrategias de la memoria", Historia, antropología y fuentes orales, $\mathrm{n}^{-} 32$ (2004), 69-87 y “Memoria e historia en la vida
}

del "sujeto", él mismo, pues el museo tenía una evidente y esencial dimensión biográfica. Era también una apuesta por el narrador, que como hemos visto hubo de reinventar el género autobiográfico y fue en esa opción estética donde la pintura cobró todo su sentido. Finalmente, ese museo pretendía un nuevo relato sobre la pintura española y el lugar que en ella debía ocupar la figura de Pablo Picasso. Al final de su vida tuvo ocasión de poder contemplar reunidas algunas de esas obras en el seno de la exposición $P i$ casso. Tradición y vanguardia. En las salas del Museo del Prado y del Museo Reina Sofía estuvo por un momento una parte, quizá la más importante, de eso que hemos dado en llamar el museo del Prado imaginario de Jorge Semprún.

\section{BIBLIOGRAFÍA}

André Malraux y España. París: Centro cultural español, 1989.

Augstein, Franziska. Lealtad y traición. Jorge Semprún y su siglo. Barcelona: Tusquets, 2010.

Calvo Serraller, Francisco. "Velázquez, Goya, Picasso...Semprún". El País, 9 de junio de 2011.

Cruz Ruiz, Juan. Especias en extinción. Barcelona: Tusquets, 2013.

Fernández, Carlos. "Jorge Semprún y las estrategias de la memoria". Historia, antropología y fuentes orales, nº 32 (2004), 69-87.

Fernández, Carlos. "Memoria e historia en la vida de Jorge Semprún". Minius, XIII (2005), 253-268.

Fernández, Carlos. "Pintura y memoria en las novelas de Jorge Semprún". Historia, antropología y fuentes orales, no 46 (2011), 47-59.

Foucault, Michel. Les Mots et les choses. Paris: Gallimard, 1966.

Fox Maura, Soledad. Ida y vuelta. La vida de Jorge Semprún. Barcelona: Debate, 2016.

de Jorge Semprún", Minius, XIII (2005), 253-268. 
Fundación Amigos del Museo del Prado. http:// www.amigosmuseoprado.org/es/funda cion/proyectos-especiales/homenajes/jor ge-semprun

Gracia, Jordi. "Novelar la memoria o la libertad del escritor". En Jorge Semprún o las espirales de la memoria, editado por Xavier Pla, 87-109. Zaragoza: Reichenberger, 2010.

Malraux, André. Saturne. Essai sur Goya. Paris: La Galerie de la Pleiade, 1950.

Malraux, André. La cabeza de obsidiana. Buenos Aires: Sur, 1974.

Malraux, André. El Museo Imaginario. Madrid: Cátedra, 2017.

Millu, Liana. El humo de Birkenau. Barcelona: Acantilado, 2005.

Nicolas de Staël. Retrospectiva. Madrid: Museo Nacional Centro de Arte Reina Sofía, 1991.

Nieto, Felipe. La aventura comunista de Jorge Semprún. Barcelona: Tusquets, 2014.

Piedad y terror en Picasso. Madrid: Museo Nacional Centro de Arte Reina Sofía, 2017.

Portús, Javier. “La sala de las Meninas en el Museo del Prado o la puesta en escena de la obra maestra". Boletín del Museo del Prado, T. XXVII, no 45 (2009), 100-128.

Semprún, Jorge. Federico Sánchez se despide de ustedes. Barcelona: Tusquets, 1979.

Semprún, Jorge. La montaña blanca. Madrid: Alfaguara, 1987.

Semprún, Jorge. "El combatiente de la guerra civil española". En André Malraux y España, 11-31. París: Centro cultural español, 1989.

Semprún, Jorge. "Francisco de Goya". En Veintitrés biografías de pintores. Museo del Prado, 439-453. Madrid: Mondadori, 1992.
Semprún, Jorge. La escritura o la vida. Barcelona: Tusquets, 1995.

Semprún, Jorge. “El paso de la laguna Estigia. Joachim Patinir". En Obras maestras del Museo del Prado, 105. Madrid: Fundación Amigos del Museo del Prado / Electa, 1996.

Semprún, Jorge. Adiós, luz de veranos. Barcelona: Tusquets, 1998.

Semprún, Jorge. "Lúcida y extraordinaria". En Una invitación a la lectura, 113-115. Madrid: Clásicos del siglo XX, 2002.

Semprún, Jorge. "Les Ménines de Vélasquez". Le Nouvel Observateur, 4 de agosto de 2005

Semprún, Jorge. "Una tumba en las nubes". En Pensar en Europa, 141-156. Barcelona: Tusquets, 2006.

Semprún, Jorge. "El arte en la época de la mundialización". En Pensar en Europa, 203-224. Barcelona: Tusquets, 2006.

Semprún, Jorge. "Ahora empieza la pintura moderna". En Picasso. Tradición y vanguardia, 21-25. Madrid: Ministerio de Cultura, 2006

Semprún, Jorge. Vivir es resistir. Barcelona: Tusquets, 2014.

Semprún, Jorge. Ejercicios de supervivencia. Barcelona: Tusquets, 2016.

Staël, Nicolas de. Lettres à Jacques Dubourg. London: Taranman, 1981.

Steiner, Georges. "El erudito traidor". En Georges Steiner en The New Yorker, 27-63. Madrid: Siruela, 2009.

Thiebaut, Carlos. "La mal llamada postmodernidad (o las contradanzas de lo moderno)". En Historia de las ideas estéticas y de las teorías artísticas contemporáneas, editado por Valeriano Bozal, vol II, 311-327. Madrid: Visor, 1996. 